\title{
SURVEY OF RANDOM BLOOD SUGAR LEVELS AMONGST LEPROSY-DISABLED PEOPLE IN BANGLADESH
}

\author{
C RUTH BUTLIN ${ }^{1}$, DELWAR HOSSAIN ${ }^{2}$, SUREN SINGH ${ }^{3}$, TS WARRENDER ${ }^{4}$
}

\begin{abstract}
:
People with leprosy-related disability in north west Bangladesh were surveyed for diabetes. According to patient reports, 97 (27.1/1000) already knew they suffered from diabetes mellitus. Amongst 3573 subjects who underwent a random blood sugar test, anyone with random blood sugar level above $11.0 \mathrm{mmol} / \mathrm{l}$ was referred for confirmation of diabetes and advice (111).

Unexpectedly, we also found that $30.1 \%$ asymptomatic people without a previous diagnosis of diabetes had random blood sugar in the "impaired glucose tolerance" range (i.e. 7.8- $11.0 \mathrm{mmol} / \mathrm{l}$ ).

These people were asked to have a second blood test for fasting blood sugar level, and if this was high (above $7.0 \mathrm{mmol} / \mathrm{l}$ ) they were advised to have a review with a doctor, preferably at the local diabetic clinic. A sample of people (5\%) with Blood sugar levels in the normal range were also invited to have a second test for fasting blood sugar; amongst them only 2 had elevated fasting blood sugar levels (>7.0).

Thus another 14 were referred with high fasting blood sugar levels. Of those 125 people (considered to be Diabetes suspects) newly-detected with hyperglycaemia, 121 attended a suitable service provider for confirmation/exclusion of diabetes, within 1month of their abnormal blood test.

Of them 47 (37.6\%) were diagnosed with diabetes. However, 4 people did not take action as advised, and 2 died before attending clinic. Taking into account new diagnoses and old, we estimate a minimum prevalence of 40.3/1,000 amongst leprosy-disabled people in NW Bangladesh.

These findings indicate the advisability of routine screening for diabetes amongst people affected by leprosy during routine clinic reviews, and that the ability and motivation to manage their own self-care of people with leprosy related disability and diabetes should be assessed. Appropriate follow up and advice for those with blood sugar in impaired glucose tolerance (IGT) range needs consideration, to minimise their future risk.
\end{abstract}

Key words: diabetes, disability, impairment, leprosy, self-management, blood sugar level.

\section{Introduction}

There is an increasing prevalence of diabetes in the world but particularly in South Asia and in people of South Asian origin in the $\mathrm{UK}^{1,2}$. This appears to be higher in urban compared with rural populations but little is known of the prevalence in particular sub groups of the populations such as those who are very poor or those with other established disability. Although the well-known risk factors for diabetes are being overweight, taking a calorie-rich diet and leading a sedentary life-style. In rural North-west Bangladesh where a high proportion of the population are of low body weight and physically active, there is also a relatively high prevalence of diabetes.

The long term outlook for people with diabetes depends largely on their ability to manage their own disease, including not only attendance at clinic and compliance with prescribed medication but also diet

1. Medical Advisor, Rural health Programme (The Leprosy Mission international, Bangladesh), DBLM hospital, Notkhana, Nilphamari P.O., District Nilphamari , 5300, Bangladesh

2. Manager, Community Programmes, TLMIB

3. Suren Singh : Programme leader, Community Programmes, TLMIB

4. T S Warrender: Volunteer advisor, The Leprosy Mission England and Wales

Corresponding author: CR Butlin, Medical Advisor, Rural health Programme (The Leprosy Mission international, Bangladesh), DBLM hospital, Notkhana, Nilphamari P.O., District Nilphamari , 5300, Bangladesh. E-mail:drbutlin@yahoo.com 
control, adequate exercise, observation for symptoms of complications, and self-care of sensory impaired limbs. Anyone suffering another physical disability or a social disadvantage such as poverty or marginalisation, will be further handicapped and may fail to manage their diabetes effectively.

In Bangladesh until recently leprosy was common, and there are still thousands of people living with physical disability secondary to a past leprosy infection. Since the disability is largely peripheral neurological impairment there is an unfortunate overlap between complications arising from leprosy and those arising from diabetes, such that any person affected by both diseases will be in double jeopardy. There is an association between leprosy and poverty which means that many of the poorest people are already struggling with the greatest burden of disability. There is also a known association between occurrence of a major illness and descent into poverty; hence a new diagnosis of diabetes in someone already disadvantaged by leprosy may be expected to precipitate a catastrophic economic blow. We aimed to assess the prevalence of co-morbidity amongst leprosy disabled people by enquiry and blood tests to determine the proportion also suffering from diabetes.

This survey is part of a larger project aiming to identify and to empower people with both diabetes and leprosydisability, enhancing their ability to manage both conditions despite their lack of material resources. Findings in relation to known diabetes are reported elsewhere (paper accepted by Birdem Medical Journal).

\section{Materials and Methods}

\section{Study design}

The study consisted of a cross sectional survey of people known to have leprosy-related disability in 4 districts of Rajshahi division (North-West Bangladesh). For each person a random capillary blood sample was taken for blood sugar measurement and those which were found to be high,in people not already known to be diabetic, were told they "might have diabetes" and were referred to a suitable service provider for further assessment. From most of those with intermediate levels of blood glucose second blood samples were taken for fasting blood sugar.

\section{Population\& sample}

The study population consisted of all known adult leprosy disabled people living in 4 districts of NW Bangladesh. Those registered for annual disability follow up because they were known to have a disability (or multiple disability) arising from leprosy, either consisting of peripheral nerve damage and its consequences or visual impairment due to leprosy (WHO disability grade 1 or 2 at release from treatment, or at diagnosis if still under Multi drug therapy) were considered eligible. The survey was carried out by field staff of an international NGO (The Leprosy Mission International) in a well-established leprosy control project dedicated to clinical and epidemiological research, which works in cooperation with the national leprosy control programme. All living eligible individuals were to be contacted via mobile phone, by home visits or when they attended clinics. With their informed consent they were enrolled for the study, whether or not they were already known to have diabetes.

\section{Methods}

Individuals who gave informed consent were asked whether they were aware of having diabetes. A finger prick blood sample was taken for random blood sugar levels and tested immediately by a hand held glucometer. Time of testing was noted.

Subjects' biodata was recorded including age, weight and height (for calculation of body mass index). The person's current leprosy status was checked and recorded (duration of disease, multidrug therapy received, present level of disability and presence of any acute complications such as leprosy reaction, or current consumption of steroids for reaction). Leprosy-related disability was measured according to WHO disability grading and the eye hand foot score. According to the standard WHO system ${ }^{3}$, grade 0 indicates no disability, grade 1 represents anaesthesia or other non-visible disability of limbs and grade 2 is given if there is visible disability of hands/feet (such as resorption or trophic ulcers)or if there is loss of vision $(<6 / 60)$ or lagophthalmos; the maximum score of any one site is taken as the overall grade. For the Eye Hand Foot score (EHF), a similar but more detailed scoring system, ${ }^{4}$ the "WHO disability level" scores for 6 individual sites are summated.

Any subject with a RBSL above the threshold of 11 $\mathrm{mmol} / 1$ was referred for medical advice (at the local diabetic clinic/government health facility). Individuals were asked to attend with the letter within 2 weeks of the blood test. Staff followed up people who had had abnormal results to find out whether they had attended or not. Subjects with intermediate blood sugar results $(7.1-11 \mathrm{mmol} / \mathrm{l})$ were invited to have a second blood test when fasting.

Newly diagnosed and known diabetic cases were informed that they would later be invited to participate in an educational/empowerment intervention. 
WHO criteria for diagnosis of diabetes state that ${ }^{5}$ for asymptomatic people a single RBSL of over 11.1 $\mathrm{mmol} / 1$ or a single fasting BSL of over $7.0 \mathrm{mmol} / 1$ is diagnostic of diabetes. Two abnormal results on separate occasions are preferable. Random Blood sugar results in range 7.8-11.1 are considered to represent "impaired glucose tolerance" if the fasting BSL was also $<7.0 \mathrm{mmol} / 1$ (sometimes called prediabetes); such people are at increased risk of developing diabetes within a few years

\section{Analysis}

Data collected in the field on paper sheets were transferred to a computer database by a trained data entry clerk and analysed using MS Excel.

For survey purposes, a subject was considered to be a diabetes suspect if RBSL $>11 \mathrm{mmol} / 1$ or a fasting blood sugar over $7.0 \mathrm{mmol} / 1^{5}$. For definite diagnosis of diabetes a second test is required (unless the patient was symptomatic at the time of testing). The outcome of referrals, for further assessment \& medical advice at a clinic, was recorded as NonAttendance, Diabetes confirmed, Follow-up advised, or Diabetes excluded.

\section{Results}

From the computer database and clinic staff personal knowledge, a total list of 4603 potential subjects was composed. Amongst them, 816 were reported to have died earlier, 209 could not be contacted and 5 refused participation, leaving 3573 eligible people who were tested (94.35\% of eligible living leprosy-disabled population). [See Table 1.]

Table-1

Reason for exclusion from the survey.

\begin{tabular}{lccc}
\hline Reason for exclusion & Male & Female & Totals \\
\hline Died & 664 & 152 & 816 \\
Working away & 81 & 22 & 103 \\
Living away & 44 & 15 & 59 \\
Not at home & 29 & 18 & 47 \\
Refused test & 2 & 3 & 5 \\
No data & 0 & 0 & 0 \\
Sub-Totals & 820 & 210 & 1030 \\
\hline
\end{tabular}

Subjects who were screened AND NOT KNOWN to have diabetes AND not found to have diabetes

There were 97 subjects who stated they already knew they had diabetes. We have no reason to think those not tested differed significantly from those tested.

The $\mathrm{b}$ iodata and leprosy characteristics of these subjects who were testedare shown in Tables 2 to 6 .

Table-II

Subjects who were screened AND NOT KNOWN to have diabetes AND not found to have diabetes.

\begin{tabular}{lccccccc}
\hline & subjects & RFT & UT & DG1 & DG2 & PB & MB \\
\hline Male & 2480 & 2357 & 123 & 884 & 1596 & 685 & 1795 \\
& $72.3 \%$ & $95.0 \%$ & $5.0 \%$ & $35.6 \%$ & $64.4 \%$ & $27.6 \%$ & $72.4 \%$ \\
Female & 949 & 894 & 55 & 390 & 559 & 286 & 663 \\
& $27.7 \%$ & $94.2 \%$ & $5.8 \%$ & $41.1 \%$ & $58.9 \%$ & $30.1 \%$ & $69.9 \%$ \\
\multirow{2}{*}{ Totals } & 3429 & 3251 & 178 & 1274 & 2155 & 971 & 2458 \\
& $100.0 \%$ & $94.8 \%$ & $5.2 \%$ & $37.2 \%$ & $62.8 \%$ & $28.3 \%$ & $71.7 \%$ \\
\hline
\end{tabular}

Subjects who were screened AND who were NOT KNOWN to have diabetes but FOUND to have diabetes

Table-III

Subjects who were screened AND who were NOT KNOWN to have diabetes but FOUND to have diabetes.

\begin{tabular}{lccccccc}
\hline subjects & RFT & UT & DG1 & DG2 & PB & MB & \\
\hline Male & 34 & 32 & 2 & 13 & 21 & 6 & 28 \\
& $72.3 \%$ & $94.1 \%$ & $5.9 \%$ & $38.2 \%$ & $61.8 \%$ & $17.6 \%$ & $82.4 \%$ \\
Female & 13 & 12 & 1 & 7 & 6 & 6 & 7 \\
& $27.7 \%$ & $92.3 \%$ & $7.7 \%$ & $53.8 \%$ & $46.2 \%$ & $46.2 \%$ & $53.8 \%$ \\
Totals & 47 & 44 & 3 & 20 & 27 & 12 & 35 \\
& $100.0 \%$ & $93.6 \%$ & $6.4 \%$ & $42.6 \%$ & $57.4 \%$ & $25.5 \%$ & $74.5 \%$ \\
\hline
\end{tabular}

Subjects who were screened and previously known to have diabetes 
Table-IV

Subjects who were screened and previously known to have diabetes

\begin{tabular}{|c|c|c|c|c|c|c|c|}
\hline & subjects & RFT & UT & DG 1 & DG2 & PB & $\mathrm{MB}$ \\
\hline \multirow[t]{2}{*}{ Male } & 66 & 61 & 5 & 22 & 44 & 17 & 49 \\
\hline & $68.0 \%$ & $92.4 \%$ & $7.6 \%$ & $33.3 \%$ & $66.7 \%$ & $25.8 \%$ & $74.2 \%$ \\
\hline \multirow[t]{2}{*}{ Female } & 31 & 29 & 2 & 17 & 14 & 10 & 21 \\
\hline & $32.0 \%$ & $93.5 \%$ & $6.5 \%$ & $54.8 \%$ & $45.2 \%$ & $32.3 \%$ & $67.7 \%$ \\
\hline \multirow[t]{3}{*}{ Totals } & 97 & 90 & 7 & 39 & 58 & 27 & 70 \\
\hline & $100.0 \%$ & $92.8 \%$ & $7.2 \%$ & $40.2 \%$ & $59.8 \%$ & $27.8 \%$ & $72.2 \%$ \\
\hline & & 97 & 97 & 97 & & & \\
\hline
\end{tabular}

Table -V

All subjects who were screened

\begin{tabular}{|c|c|c|c|c|c|c|c|}
\hline & subjects & RFT & UT & DG 1 & DG2 & PB & $\mathrm{MB}$ \\
\hline \multirow[t]{2}{*}{ Male } & 2580 & 2450 & 130 & 919 & 1661 & 708 & 1872 \\
\hline & $72.2 \%$ & $95.0 \%$ & $5.0 \%$ & $35.6 \%$ & $64.4 \%$ & $27.4 \%$ & $72.6 \%$ \\
\hline \multirow[t]{2}{*}{ Female } & 993 & 935 & 58 & 414 & 579 & 302 & 691 \\
\hline & $27.8 \%$ & $94.2 \%$ & $5.8 \%$ & $41.7 \%$ & $58.3 \%$ & $30.4 \%$ & $69.6 \%$ \\
\hline \multirow[t]{3}{*}{ Totals } & 3573 & 3385 & 188 & 1333 & 2240 & 1010 & 2563 \\
\hline & $100.0 \%$ & $94.7 \%$ & $5.3 \%$ & $37.3 \%$ & $62.7 \%$ & $28.3 \%$ & $71.7 \%$ \\
\hline & & 3573 & 3573 & 3573 & & & \\
\hline
\end{tabular}

Table-VI

Characteristics of different groups of subjects

\begin{tabular}{llccc}
\hline & & Mean age & Mean yrs of leprosy & Mean EHF score \\
\hline Non diabetics & Total & 54.5 & 19.8 & 3.3 \\
& Male & 54.8 & 20.0 & 3.3 \\
& Female & 53.7 & 19.2 & 3.3 \\
Newly diagnosed diabetics & Total & 57.9 & 18.7 & 2.8 \\
& Male & 59.7 & 19.0 & 3.2 \\
& Female & 53.1 & 18.2 & 3.8 \\
Previously known diabetics & Total & 55.5 & 19.1 & 3.9 \\
& Male & 54.6 & 19.7 & 3.6 \\
& Female & 51.9 & 18.0 & 3.2 \\
& Total & 54.2 & 19.7 & 3.2 \\
\hline
\end{tabular}




\section{Biodata}

The subjects were spread over a wide range of ages, with similar distribution pattern for male and for female (Table VII and Figure 1).Children had been excluded from the study.

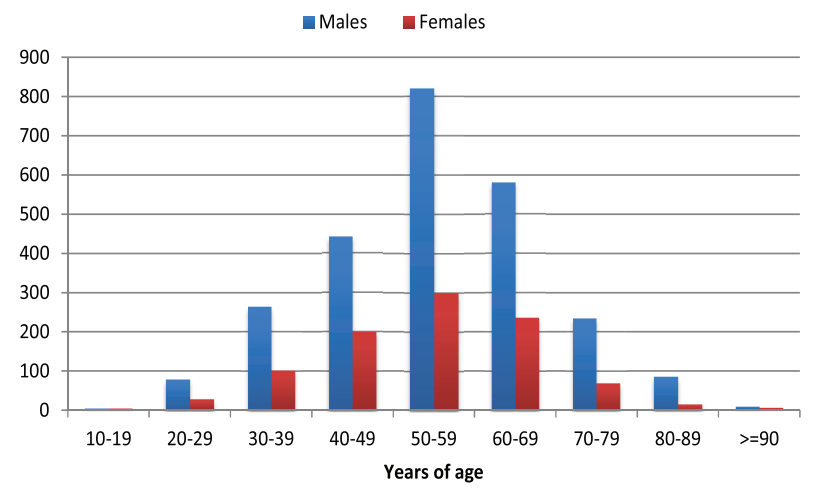

Fig.-1: Age Distribution for KNOWN diabetics

For further analysis, the 97 known diabetics are deducted from total subjects and reported separately for comparison (Table-VIII).

\section{Leprosy history}

The subjects had on average been diagnosed with leprosy about 20years ago (Table VI) and about 95\% were already released from treatment after multidrug therapy (Table 5). Hence the majority were no longer at risk of leprosy reaction which might require steroid therapy. There will be some correlation between age and time since leprosy diagnosis (Tables 9) and (Figures 2 and 3) show duration of leprosy (by diabetic status and gender), in 5 year intervals.

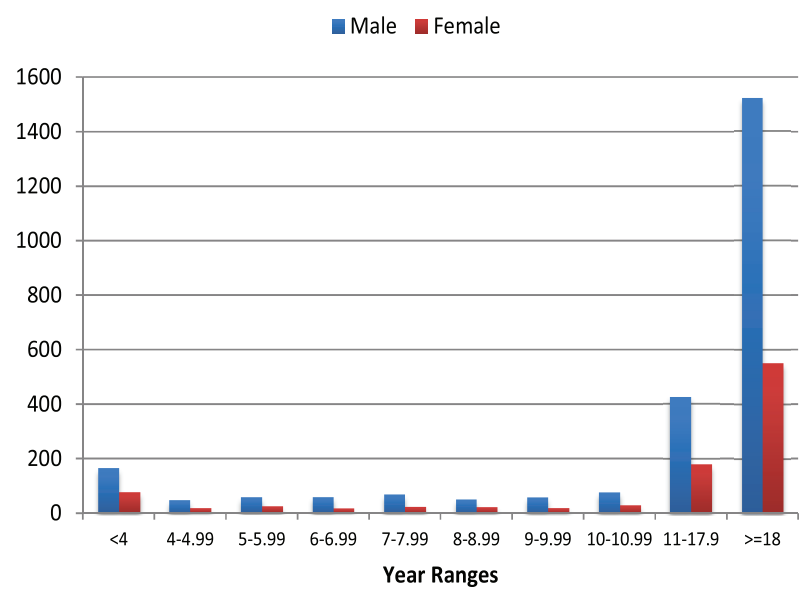

Fig.-2: Years ranges of those screened not known to have diabetes

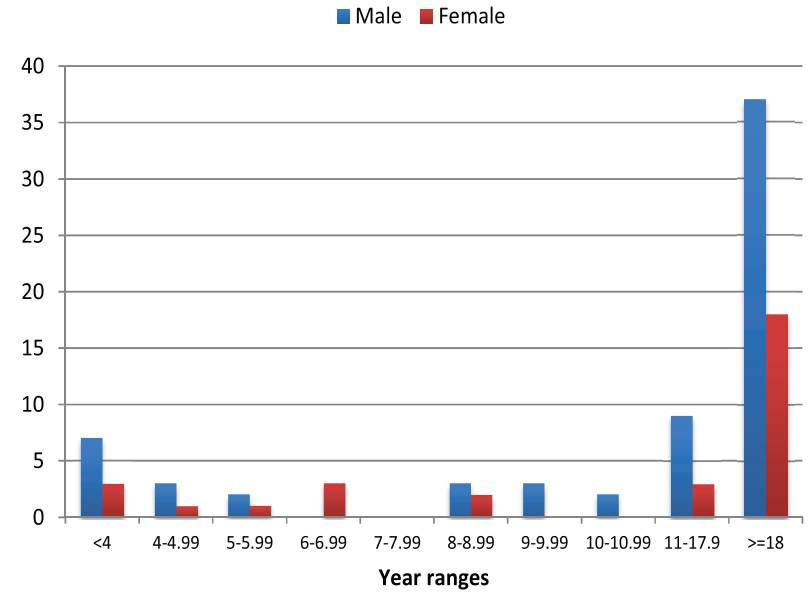

Fig.-3: Years of leprosy for subjects known to have diabetes

Table-VII

Age/Sex distribution of those screened with no known diabetes

\begin{tabular}{|c|c|c|c|c|c|}
\hline Age Bands (yrs) & Males & Females & Totals & Males \% & Female \% \\
\hline $10-19$ & 5 & 5 & 10 & $0 \%$ & $1 \%$ \\
\hline $20-29$ & 77 & 28 & 105 & $3 \%$ & $3 \%$ \\
\hline 30-39 & 264 & 102 & 366 & $11 \%$ & $11 \%$ \\
\hline $40-49$ & 441 & 200 & 641 & $18 \%$ & $21 \%$ \\
\hline $50-59$ & 820 & 300 & 1120 & $33 \%$ & $31 \%$ \\
\hline $60-69$ & 579 & 236 & 815 & $23 \%$ & $25 \%$ \\
\hline $70-79$ & 234 & 70 & 304 & $9 \%$ & $7 \%$ \\
\hline $80-89$ & 86 & 16 & 102 & $3 \%$ & $2 \%$ \\
\hline$>=90$ & 8 & 5 & 13 & $0 \%$ & $1 \%$ \\
\hline Totals & 2514 & 962 & 3476 & $100 \%$ & $100 \%$ \\
\hline
\end{tabular}


Table-VIII

Age Distribution for KNOWN diabetics

\begin{tabular}{lccccc}
\hline Age/Sex & Males & Females & Totals & Males $\%$ & Female $\%$ \\
\hline $10-19$ & 0 & 0 & 0 & $0 \%$ & $0 \%$ \\
$20-29$ & 2 & 1 & 3 & $3 \%$ & $3 \%$ \\
$30-39$ & 3 & 5 & 8 & $5 \%$ & $16 \%$ \\
$40-49$ & 14 & 5 & 19 & $21 \%$ & $16 \%$ \\
$50-59$ & 18 & 11 & 29 & $27 \%$ & $35 \%$ \\
$60-69$ & 20 & 1 & 28 & $30 \%$ & $26 \%$ \\
$70-79$ & 7 & 0 & 2 & $11 \%$ & $3 \%$ \\
$80-89$ & 2 & 0 & 0 & $3 \%$ & $0 \%$ \\
$>=90$ & 0 & 31 & 97 & $100 \%$ & $0 \%$ \\
\hline Totals & 66 & & & & $100 \%$ \\
\hline
\end{tabular}

Years of leprosy for subjects not known to have diabetes

\section{Disability levels}

The subjects had by definition, some degree of leprosy disability, the mildest possible would be one hand or one foot with sensory impairment (EHF score of 1), but some had all 4 limbs and both eyes damaged by leprosy (Tables 10 and Figures 4, 5).The high degree of disability is partly related to the long duration of disease in many cases, since sensory loss can lead to increased disability from external trauma long after the leprosy disease is cured/inactive

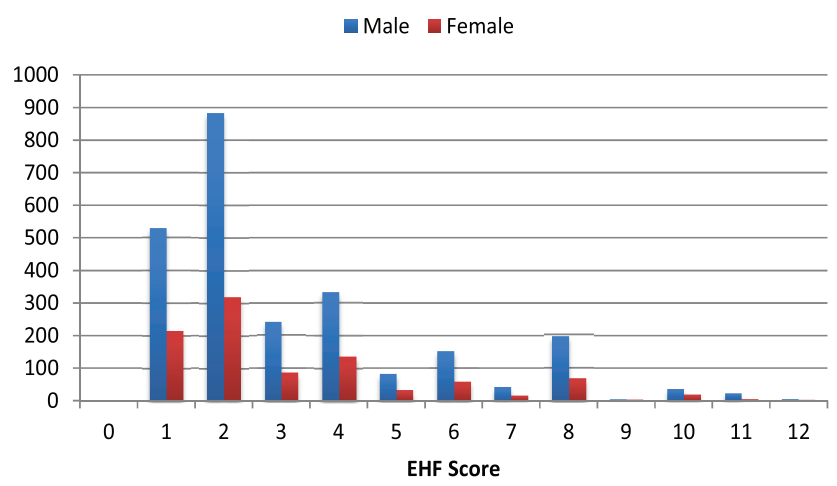

Fig.-4: EHF Scores for screened patients not known to have diabetes

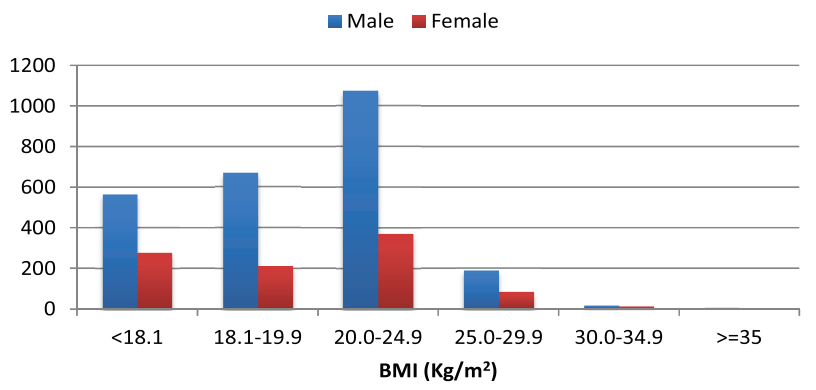

Fig.-5: BMIs for screened patient not known to be diabetic.
Table-IX

Duration of leprosy in subjects not previously known to have diabetes.

\begin{tabular}{lccc}
\hline Range (years) & Male & Female & Totals \\
\hline$<4$ & 162 & 77 & 239 \\
$4-4.99$ & 46 & 18 & 64 \\
$5-5.99$ & 55 & 24 & 79 \\
$6-6.99$ & 56 & 17 & 73 \\
$7-7.99$ & 67 & 23 & 90 \\
$8-8.99$ & 49 & 22 & 71 \\
$9-9.99$ & 58 & 20 & 78 \\
$10-10.99$ & 76 & 30 & 106 \\
$11-17.9$ & 425 & 180 & 605 \\
$>=18$ & 1520 & 551 & 2071 \\
\hline Totals & 2514 & 962 & 3476 \\
\hline
\end{tabular}

Table-X

EHF Scores for screened patients not known to have diabetes.

\begin{tabular}{lccc}
\hline EHF Score & M+ale & Female & Total \\
\hline 0 & 0 & 0 & 0 \\
1 & 529 & 215 & 744 \\
2 & 883 & 319 & 1202 \\
3 & 239 & 87 & 326 \\
4 & 332 & 137 & 469 \\
5 & 81 & 33 & 114 \\
6 & 151 & 59 & 210 \\
7 & 40 & 15 & 55 \\
8 & 195 & 69 & 264 \\
9 & 5 & 4 & 9 \\
10 & 34 & 18 & 52 \\
11 & 22 & 5 & 27 \\
12 & 3 & 1 & 4 \\
\hline Totals & 2514 & 962 & 3476 \\
\hline
\end{tabular}


Table-XI

BMIs for screened patient not known to be diabetic

\begin{tabular}{lccccccc}
\hline BMI & $<18.1$ & $18.1-19.9$ & $20.0-24.9$ & $25.0-29.9$ & $30.0-34.9$ & $>=35$ & Total \\
\hline Male & 563 & 669 & 1074 & 189 & 17 & 2 & 2514 \\
Female & 278 & 213 & 371 & 86 & 13 & 1 & 962 \\
\hline Total & 841 & 882 & 1445 & 275 & 30 & 3 & 3476 \\
\hline
\end{tabular}

Table -XII

Random blood sugar levels for subjects not known to have diabetes

\begin{tabular}{lccccccccccc}
\hline RBSL $(\mathrm{mMol} / 1)$ & $<4.0$ & $4.0-4.9$ & $5.0-5.9$ & $6.0-6.9$ & $7.0-7.9$ & $8.0-8.9$ & $9.0-9.9$ & $10.0-10.9$ & $11.0-17.9$ & $>=18$ & Totals \\
\hline Male & 10 & 136 & 376 & 636 & 620 & 386 & 209 & 60 & 69 & 12 & 2514 \\
Female & 7 & 60 & 174 & 228 & 237 & 149 & 57 & 24 & 24 & 2 & 962 \\
\hline Total & 17 & 196 & 550 & 864 & 857 & 535 & 266 & 84 & 93 & 14 & 3476 \\
\hline
\end{tabular}

\section{Body mass index (BMI)}

The distribution of BMI amongst subjects showed a preponderance of low BMI, in these apparently healthy people which may reflect long term poor nutrition. See Tables 11 and Figures 5.

\section{Blood sugar results}

Tables12,13and Figure 6:distribution for all subjects not known diabetic (by sex/age).

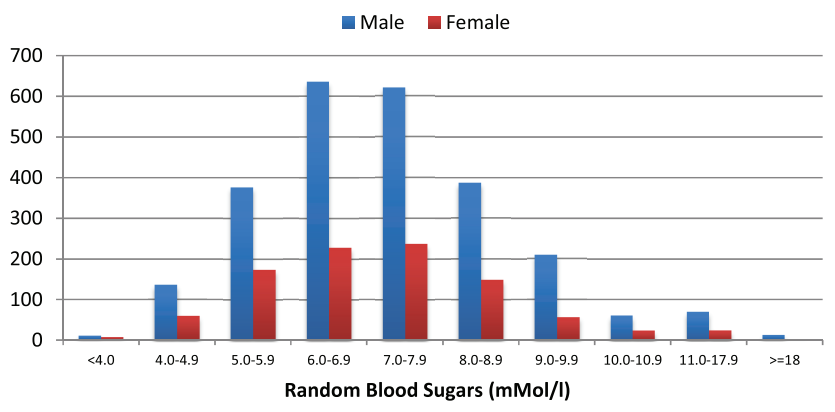

Fig.-6: Random blood sugar levels for subjects not known to have diabetes

There were 97 people (3\%) who were not known diabetics with RBSL>11.1 mmol/1 and 14 (0.3\%) of them had RBSL of 18 or more and were referred for further assessment (42 were confirmed as diabetic). Also 51 known diabetics had RBSL>11.0 (of which 20 had RBSL>18.0) and these will be discussed in another paper.

\section{Impaired glucose tolerance}

One unexpected finding was that a high proportion of subjects had RBSL below 11.1 but above $7.8 \mathrm{mmol} /$ $1(1048=30.1 \%)$, i.e. within the "impaired glucose tolerance range". These subjects were similar to other subjects in respect to age, BMI, leprosy characteristics and gender.
Table -XIII

$R B G$ Ranges for those not known to be Diabetic, with percentages.

\begin{tabular}{lccc}
\hline RBG Ranges & Males & Females & Totals \\
\hline$<7.8$ & 1667 & 664 & 2331 \\
$7.8-11.0$ & 773 & 275 & 1048 \\
$>11.0$ & 74 & 23 & 97 \\
\hline Totals & 2514 & 962 & 3476 \\
\hline
\end{tabular}

\section{Percentages}

\begin{tabular}{lccc}
\hline RBG Ranges & Males & Females & Totals \\
\hline$<7.8$ & $66 \%$ & $69 \%$ & $67 \%$ \\
$7.8-11.0$ & $31 \%$ & $29 \%$ & $30 \%$ \\
$>11.0$ & $3 \%$ & $2 \%$ & $3 \%$ \\
\hline Totals & $100 \%$ & $100 \%$ & $100 \%$ \\
\hline
\end{tabular}

\section{Fasting blood sugar results}

All those subjects with intermediate RBSL, and a randomly selected approximately $50 \%$ sample of those with "normal" RBSL $(<7.8 \mathrm{mmol} / 1)$ were retested by fasting blood sugar levels: (Table-XIV).

Amongst them 14had high FBSL and were referred to clinic as diabetes suspects; of these 5 were confirmed as being diabetic.

Amongst those subjects whose first (random BSL)blood test was in normal range $(<7.8)$, only $7 /$ 1426 who were retested with FBSL had high fasting levels(>7.0). (Table XV) 
Table-XIV

Random blood sugars on $y$-axis and fasting blood glucose on $x$-axis

\begin{tabular}{|c|c|c|c|c|c|c|c|c|c|c|c|c|c|c|c|c|c|c|c|}
\hline & $<=4.0$ & $\begin{array}{l}4.0- \\
4.9\end{array}$ & $\begin{array}{l}5.0- \\
5.9\end{array}$ & $\begin{array}{l}6.0- \\
6.9\end{array}$ & $\begin{array}{l}7.0- \\
7.9\end{array}$ & $\begin{array}{l}8.0- \\
8.9\end{array}$ & $\begin{array}{l}9.0- \\
9.9\end{array}$ & $\begin{array}{l}10.0- \\
10.9\end{array}$ & $\begin{array}{r}-11.0- \\
11.9\end{array}$ & $\begin{array}{r}-12.0 \\
12.9\end{array}$ & $\begin{array}{r}-13.0- \\
13.9\end{array}$ & 14.91 & $\begin{array}{l}15.0- \\
15.9\end{array}$ & $\begin{array}{r}-16.0- \\
16.9\end{array}$ & $\begin{array}{l}17.0- \\
17.9\end{array}$ & $\begin{array}{r}-18.0- \\
18.9\end{array}$ & $\begin{array}{c}19.0-> \\
19.9\end{array}$ & $>=20$ & Totals \\
\hline$<=4.0$ & 6 & 4 & 3 & 1 & 0 & 0 & 0 & 0 & 0 & 0 & 0 & 0 & 0 & 0 & 0 & 0 & 0 & 0 & 14 \\
\hline $4.0-4.9$ & 39 & 63 & 11 & 1 & 0 & 0 & 0 & 0 & 0 & 0 & 0 & 0 & 0 & 0 & 0 & 0 & 0 & 0 & 114 \\
\hline $5.0-5.9$ & 110 & 168 & 48 & 3 & 2 & 0 & 1 & 0 & 0 & 0 & 0 & 0 & 0 & 0 & 0 & 0 & 0 & 0 & 332 \\
\hline $6.0-6.9$ & 179 & 255 & 89 & 13 & 1 & 0 & 0 & 0 & 0 & 0 & 0 & 0 & 0 & 0 & 0 & 0 & 0 & 0 & 537 \\
\hline $7.0-7.9$ & 182 & 239 & 89 & 5 & 3 & 0 & 1 & 0 & 0 & 0 & 0 & 0 & 0 & 0 & 0 & 0 & 0 & 0 & 519 \\
\hline $8.0-8.9$ & 116 & 158 & 69 & 5 & 3 & 3 & 0 & 0 & 0 & 0 & 0 & 0 & 0 & 0 & 0 & 0 & 0 & 0 & 354 \\
\hline $9.0-9.9$ & 56 & 78 & 33 & 4 & 1 & 0 & 0 & 0 & 0 & 0 & 0 & 0 & 0 & 0 & 0 & 0 & 0 & 0 & 172 \\
\hline $10.0-10.9$ & 17 & 28 & 7 & 1 & 0 & 0 & 0 & 0 & 0 & 0 & 0 & 0 & 0 & 0 & 0 & 0 & 0 & 0 & 53 \\
\hline $11.0-11.9$ & 8 & 9 & 3 & 4 & 0 & 0 & 0 & 0 & 0 & 0 & 0 & 0 & 0 & 0 & 0 & 0 & 0 & 0 & 24 \\
\hline $12.0-12.9$ & 3 & 6 & 3 & 0 & 0 & 0 & 0 & 0 & 1 & 0 & 0 & 0 & 0 & 0 & 0 & 0 & 0 & 0 & 13 \\
\hline $13.0-13.9$ & 2 & 1 & 0 & 0 & 0 & 0 & 0 & 0 & 0 & 0 & 0 & 0 & 1 & 0 & 0 & 0 & 0 & 0 & 4 \\
\hline $14.0-14.9$ & 0 & 0 & 0 & 2 & 0 & 0 & 0 & 1 & 0 & 0 & 0 & 0 & 0 & 0 & 0 & 0 & 0 & 0 & 3 \\
\hline $15.0-15.9$ & 1 & 0 & 0 & 0 & 0 & 0 & 0 & 0 & 0 & 0 & 0 & 0 & 0 & 0 & 0 & 0 & 0 & 0 & 1 \\
\hline $16.0-16.9$ & 0 & 0 & 0 & 0 & 0 & 0 & 0 & 1 & 0 & 0 & 0 & 0 & 0 & 0 & 0 & 0 & 0 & 0 & 1 \\
\hline $17.0-17.9$ & 0 & 0 & 0 & 0 & 0 & 0 & 0 & 0 & 0 & 0 & 0 & 0 & 0 & 0 & 0 & 0 & 0 & 0 & 0 \\
\hline $18.0-18.9$ & 0 & 0 & 0 & 0 & 0 & 0 & 0 & 1 & 0 & 0 & 0 & 1 & 0 & 0 & 0 & 0 & 0 & 0 & 2 \\
\hline $19.0-19.9$ & 0 & 0 & 1 & 0 & 0 & 0 & 0 & 0 & 0 & 0 & 0 & 0 & 0 & 0 & 0 & 0 & 0 & 0 & 1 \\
\hline$>=20$ & 0 & 2 & 0 & 0 & 0 & 0 & 0 & 1 & 0 & 0 & 0 & 0 & 0 & 0 & 0 & 0 & 0 & 0 & 3 \\
\hline Totals & 719 & 1011 & 356 & 39 & 10 & 3 & 2 & 4 & 1 & 0 & 0 & 1 & 1 & 0 & 0 & 0 & 0 & 0 & 2147 \\
\hline
\end{tabular}

Table -XV

Random and 'Fasting' blood sugars

\begin{tabular}{lcccc}
\hline & FBS $<7.0$ & FBS $>=7.0$ to $<11.1$ & FBS $>=11.1$ & Totals \\
\hline RBS $<7.8$ & 1419 & 7 & 0 & 1426 \\
RBS $>=7.8$ to $<11.1$ & 666 & 8 & 3 & 674 \\
RBS $>=11.1$ & 40 & 4 & 3 & 47 \\
\hline Totals & 2125 & 19 & 3 & 2147 \\
\hline
\end{tabular}

\section{Outcome of referrals}

Amongst subjects referred for confirmation of diagnosis, a few failed to attend a suitable centre for further tests, despite staff assistance an encouragement (possible reasons discussed below). Of those who attended $37.6 \%$ were diagnosed with diabetes on basis of further tests. From this we predict that if all our referred subjects had attended there could have been 3 more confirmed diabetics amongst them $(36.7 \%$ of $7=2.63$, who did not attend or died before attending).(Table16).

According to our data, 34\% diabetics were undiagnosed before the survey. Overall we estimate the prevalence of diabetes in this population of leprosy-disabled people to be 40.3-41.4/1000 (Table17). 
Table-XVI

Outcome from Clinic Attendance

\begin{tabular}{lcccc}
\hline & Male & Female & Totals & Percentage \\
\hline DM confirmed & 34 & 13 & 47 & $37.6 \%$ \\
DM Excluded & 53 & 18 & 71 & $56.8 \%$ \\
Did Not Attend & 4 & 0 & 4 & $3.2 \%$ \\
Died Pre-Clinic & 3 & 0 & 3 & $2.4 \%$ \\
\hline Totals & 94 & 31 & 125 & $100.0 \%$ \\
\hline
\end{tabular}

Table-XVII

Estimated Prevalence of diabetes.

\begin{tabular}{lcc}
\hline & $\begin{array}{c}\text { Number of } \\
\text { cases }\end{array}$ & $\begin{array}{c}\text { Prevalence rate/ } \\
1000 \text { population }\end{array}$ \\
\hline Known diabetics & 97 & $27.1 / 1000$ \\
Newly confirmed diabetics (high RBSL in survey) & 42 & \\
Newly confirmed diabetics (high FBSL in $2^{\text {nd }}$ survey) & 5 & \\
All newly diagnosed diabetics & 47 & \\
All confirmed diabetics & 144 & $40.30 / 1000$ \\
Estimated additional cases not yet confirmed & 3 & \\
Estimated Total diabetics in population & 147 & $41.14 / 1000$ \\
Estimated prevalence of IGT(using RBSL as proxy for $2 \mathrm{hr}$ PP BSL) & 666 & $186 / 1000$ \\
\hline
\end{tabular}

\section{Discussion}

Several surveys have been done in Bangladesh over past 20 years, showing that there is a high prevalence of diabetes and of impaired glucose tolerance in Bangladesh which seems to be increasing: from $4 \%$ in 1995 , to $5 \%$ in $2001-2005$, to $9 \%$ in $2006-1010^{6,7}$. Some authors found a disparity between urban and rural populations with estimates for urban areas consistently higher: $8.1 \%$ compared with $2.3 \%^{8}, 15.2 \%$ compared with $8.3 \%{ }^{9}$. Comparison between socio economic groups indicates higher rates in the wealthier sections of population ${ }^{9,10,11}$ and comparison between overweight/obese and those with lower BMI suggests the former have a higher prevalence ${ }^{10}$. One national survey showed that in Rajshahi division ${ }^{12}$, there was a prevalence of $10.2 \%$ and in Rangpur district $8.1 \%$, whereas nationally the figure was $9.7 \%{ }^{9}$. This suggests that in the north west of Bangladesh (where our present study was conducted) diabetes prevalence does not differ much from the national situation. Amongst leprosy-affected disabled people living in the predominantly rural North west Bangladesh we found a crude prevalence rate of4.03-
$4.14 \%$ which is lower than the range reported by most other authors for the general population of rural areas of this country.

Many authors present age adjusted prevalence figures. One limitation of this paper is that we are unable to give this calculation.

The prevalence of pre-diabetes/impaired glucose tolerance in Bangladesh is consistently found to be much higher than the rate of overt diabetes. This was the case even 20 years ago ${ }^{13}$ and more recent estimates range from 12.4\% in "rural Bangladesh" 11 , to $22.4 \%$ overall and $23 \%$ in Rajshahi division ${ }^{12}$. Our finding of $18.6 \%$ amongst leprosy-disabled people is in line with these other estimates.

Most authors used fasting blood glucose plus/minus a 2-hour post prandial sample for their surveys whereas we used Random blood sugar for the main survey. This limits the comparability of the results, but some authors report good agreement between fasting and postprandial blood sugar levels ${ }^{6}$.

When a disease is very common- as diabetes now is in S Asia- inevitably there will be some individuals 
who have diabetes as well as another chronic disabling disease. At present there is no suggestion that either diabetes predisposes to leprosy or the reverse (excluding the contribution of steroid use for leprosy reaction causing some cases of hyperglycaemia). However, the two diseases will interact in their effect on a person's life and his/her ability to successfully undertake self- management. Since registered leprosy prevalence figures (collected under NLEP) ${ }^{14}$ reflect only those leprosy-affected people still on multidrug therapy, they will grossly underestimate the number of leprosy disabled people in the country. There is no reliable data at a national level for cumulative prevalence of leprosy disability. However, in our 4 districts, we identified 3787 live individuals with leprosy related disability out of a population of $7,878,854$, which is $0.048 \%$ in a population of this previously highly endemic area. Hence one might estimate that about $0.05 \%$ of all diabetics in the area could be also leprosy disabled. Conversely, if the diabetes prevalence in general population is $7-10 \%$, a similar proportion of leprosy disabled people would also be expected to have diabetes. We found a somewhat lower rate, but that could be due to the fact that the leprosy disabled people were on average of low BMI and in lower socio economic classes, i.e. they had reduced level of other risk factors for diabetes.

We found a dearth of other papers on the coprevalence of diabetes and leprosy. One survey in India found $15 \%$ residents of a "leprosy slum colony" were diabetic; their sample included 63/133 disabled15.By comparison in this study of disabled leprosy-affected people living in the community we found 47 previously undiagnosed diabetics as well as97 known diabetics (total144=4\%)

Amongst our subjects there was a subgroup with very high BSL (>18). According to WHO advice ${ }^{11}$ such patients need urgent intravenous fluids and immediate referral to hospital. Of these 14 did not previously know they had diabetes.

The importance of the high proportion of subjects with BSL in intermediate range (who may have IGT) is unclear. It would be useful to do a longitudinal study of these subjects to know what proportion develops diabetes within a few years or whether it is a transient phenomenon. In their situation as poor rural people with limited access to health care, it is not appropriate to suggest prophylactic treatment at this stage, but they might be offered general advice on limiting their risk of diabetes such as to avoid becoming overweight. In "western "/high-income countries such people would be actively followed up perhaps by annual screening.
The significance of the small number of subjects (4) who voluntarily had their blood tested at home but then were unable/unwilling to go for confirmation of an abnormal result requires careful attention. Some of the possible factors which could explain this are as follows: people without symptoms unable to believe they have a serious disease like diabetes, real or imagined barriers to attending the clinic (distance, cost, social factors such as a woman needing a male companion to travel), possibly an unfounded hope that the field staff who had approached them unsolicited and done their test would bring further testing \& treatment to their home. These issues need further exploration, which we intend to do in the next phase of our project.

On the other hand, the high proportion of referred cases who were not confirmed diabetes on further testing (57\% of those assessed), although their random blood sugar was over $11 \mathrm{mmol} / 1$ on one occasion, makes us wonder whether the specificity of a single random blood sugar test is high enough for it to be used as a screening tool in an asymptomatic population. Our initial premise had been that this test was a useful screening tool. We are currently running a hospital based study to compare sensitivity $\&$ specificity of random and fasting blood sugars as the initial screening test for diabetes in this population.

In phase 2 of our project we intend to offer an educational interventions designed to empower diabetics with leprosy disability for enhancing selfefficacy \& resultant better self-management

Limitations of this study: for pragmatic reasons, mainly the convenience of the subjects, our original survey used only random blood sugar levels, which we expected to be similar to (not higher than) 2-hour post prandial samples in same persons would be.If one only does a $2 \mathrm{hrs}$ Post Prandial BSL one would miss $30 \%$ diabetics ${ }^{5}$ but these have worse prognosis, so are the more important cases to diagnose.

Our testing was by capillary blood, whereas venous blood or venous plasma samples might have given slightly different results. However, the additional discomfort and minor extra risk to subjects of venepuncture (versus finger prick), additional staff training which would be involved to collect venous blood, and the difficulties of transporting samples to the central laboratory before they deteriorated, could not be justified by the small expected increase in accuracy of data. 
We do not have contemporaneous data for nonleprosy-affected people living in the same areas with similar biodata to our subjects. However, there is no a priori reason to suppose that having had leprosy would affect their glucose metabolism. Hence we feel it adequate to compare our findings with those of others who studied rural Bangladeshi populations.

The estimates of prevalence rates are compromised by the small proportion of subjects whose initial blood test was "abnormal" for whom we do not have confirmation of their diabetic status by a physician's assessment and repeat blood tests at a clinic.

\section{Conclusion}

In this population of leprosy affected people the total prevalence of undetected diabetes (using threshold for diagnosis as recommended by WHO) is not dissimilar to levels reported by other authors for the general population. In view of their increased susceptibility to complications and reduced capacity for self- management of diabetes, consideration should be given to active screening of people diagnosed with leprosy either at thestart of MDT or at RFT, and appropriate education about signs and symptoms of diabetes.

The prevalence of "impaired glucose tolerance" also appears to be high. How to manage this issue is currentlyunder consideration, particularly in the light of our experience that many people with a single high blood sugar test will not themselves undertake follow up.

A further study is planned to elucidate the problems encountered by such individuals (as a direct result of physical disability, or because of associated problems such as disempowerment/social marginalisation/ low health literacy/ poverty) and to assess the effect of an intervention designed to empower them for better self-management.

\section{References}

1. Anonymous, "non communicable disease burden in Bangladesh", editorial Birdem medical journal 2012, 2 (1) p31,

2. Sproston K, Mindell $\mathrm{J}$ (for health and social care information centre). Health Survey of England 2004, Health of minority ethnic groups. available from www.hiscic.gov.uk (accessed Jan 2016)

3. WHO, Expert committee on leprosy, $6^{\text {th }}$ report, technical report series 768,1988
4. Bassey- Ebenso, Monitoring impairment in leprosy: choosing the appropriate tool. Leprosy Review 2007, 78, p270-280

5. WHO criteria for diagnosis of diabetes Definitions and diagnosis of diabetes mellitus and intermediate hyperglycaemia. Report of a WHO/IDF consultation, WHO 2006

6. Saquib N, Saquib J, Ahmed T et al, 2012 BMC Public healthp 434 "cardiovascular disease and type 2 diabetes in Bangladesh: a systematic review and meta-analysis of studies between 1995-2010"

7. Rahim MA, Hussain A, Azad Khan AK, Sayeed MA, Keramet Ali S,M,\& Vaaler S,"Rising prevalence of type 2 diabetes in rural Bangladesh: a population based study" , 2007, Dia. Res. Clin. Practice, 77, p300-305. doi:http://dx.doi.org/10.1016/ j.diabetes.2006/11.010 PMID 17187890

8. Hussain A, Rahmin MA, Azad Khan AK \& Vaaler S, 2005"Type 2 diabetes in rural and urban populations: diverse prevalence and associated risk factors in Bangladesh " Diab med 22,931-6

9. Shamin Akter 2014, Bulletin WHO"Prevalence of diabetes and pre diabetes and their risk factors amongst Bangladeshi adults: a nationwide survey". Bulletin WHO, 92, p204-213A doi:http:// dx.doi.org/10.2471/BLT.13.128371

10. Abu Sayed M, 1997"Effect of socio economic risk factors on difference in prevalence of diabetes between rural and urban populations in Bangladesh". Diabetes care, 20, p 551-5 doi:http:/ /dx.doi.org/10.2337/diacare.20.4.551 PMID: 9096979

11. Abu Sayed M, 2003"Diabetes and impaired fasting glycaemia in rural population in Bangladesh. Diabetes care 2003, 26, 4 p 1034-39Doi 10.2337/ diacare.26.4.1034

12. Shamin Akter 2014, "Nationwide survey of prevalence and risk factors for diabetes and pre diabetes in Bangladeshi adults", Jan 2014, Diab care vol37 doi e9-e10/doi:102337/dc13-1647

13. Abu Sayeed M, Banu A, Khan AR, Hussain MZ,1995, "prevention of diabetes and hypertension in a rural population in Bangladesh"1995, Diabetes care, 18, 555-8,

14. WHO, 2014, weekly epidemiological record, 89, p389-400 "Global leprosy update 2013: reducing leprosy burden"(for Bangladesh leprosy statistics )

15. RK Singh, S Kumar, LBSingh, "diabetic status of leprosy patients in referral centres of Bihar and Jharkand". Abstracts of International Leprosy Congress 2013, 0-230 